anterior del tema" y que el fin buscado con la publicación de sus páginas es realizar una exposición de lo que puede expresarse, con un criterio lo más independiente posible, en pro y en contra de aquellas soluciones que las más trascendentes escuelas filosóficas han venido proponiendo - a través del tiempo y del espacio frente a los principales problemas del pensamiento, de la búsqueda de la verdad, de la vida espiritual.

La posición de Brightman es francamente idealista. El sabe muy bien que en los tiempos actuales se juega con los vocablos y se anticipa a la prevención que algunos tendrán frente a su credo filosófico. Dice, con mucha razón que "las cosas han llegado a tal extremo, que el idealismo de Platón halla cabida en la élite de los círculos filosóficos sólo cuando se le llama realismo. Algunos idealistas contemporáneos hallan refugio bajo otras banderas, tales como la del 'pluralismo espiritualista' o la del 'realismo personal'. Los nombres significan poco; menos aún la moda; sólo ha de tomarse en cuenta la verdad".

A la búsqueda de la. verdad, en el plano filosófico, dedica esta densa obra, bien estructurada, redactada en un estilo ágil, subdividida en numerosos capítulos, y llamada a hacer meditar: tal es, a nuestro juicio, su principal mérito, aparte de la erudición sintetizada en sus páginas, cuya traducción española es correcta.

La edición, sobria y fina, forma parte de una serie de interesantes publicaciones.

$* \quad * \quad *$

Eduardo Campos, Face iluminada.-Fortaleza (Ceará, Brasil). Edições Clã, 1946. 124 pp.

El primer libro de cuentos de este joven escritor, fué publicado en 1943, con el título de Aguas mortas, mereciendo elogiosos comentarios de valores tan significativos como Mario de Andrade, Carlos Drummond de Andrade, Sergio Milliet, etc.

En este su segundo libro de narraciones breves, Eduardo Campos ahonda más las virtudes de aquel tomo inicial: continúa revelando su gran conocimiento de la vida y del alma humana, en sus reacciones, en sus ilusiones, en sus desengaños. Ahora, es mayor su dominio técnico, su don de interesar al lector. Por la depuración de su prosa, Face iluminada posee mayor jerarquía estética que Aguas mortas. 
Sus diálogos son naturalísimos, sin ningún artificio; sus descripciones, nítidas y rotundas y en muchos casos hay un sobrio toque poemático. De esto da fe su cuento "A solteirona dos olhos tristes", una de las páginas más emotivas de este bello libro.

$$
* * *
$$

Alberto Girrr, Playa sola.-Buenos Aires. Edit. Nova, 1946. 72 pp.

He aquí un bellísimo libro, cuyos veintiún poemas nos dan, con fuerza y delicadeza a la vez, un mundo lírico pleno de emoción y de sugerencias, en la pureza de su verdad mágica, que es la verdad cotidiana depurada por un temperamento artístico, sublimada por la sensibilidad y la imaginación.

Alberto Girri se expresa noblemente en el verso libre, tan arduo por su declive al prosaísmo. Pero el verso de Playa sola posee una música interna, que se hermana al tono confesional de su emoción:

De mi paseo por la repetición nocturna traje un niño acróbata, acorazado de impureza y de ilusión:

"Allá arriba, confiado en ese dios solitario la carne desaparece.

Abajo el deseo me hincha y no puedo morir". Confuso, menos intacto, siento hambre de frescura lunar.

El carácter un tanto penumbral de estos poemas los dirige a las minorías, a quienes quieren ser - humilde y fervorosamente- colaboradores del poeta, "rodeado de misterio" como dice en "El examen", uno de sus máximos poemas.

La zona lírica de este argentino es, a veces, de un patetismo desgarrado, que armoniza con cierta aguda y fina ironía. Su voz suena nueva en el coro de la actual poesía del Plata.

Playa sola aparece en un tomo muy pulcro, de la colección "Paloma", prologado por Lorenzo Varela y con una muy expresiva viñeta de Seoane.

\section{Gastón Figueira}

